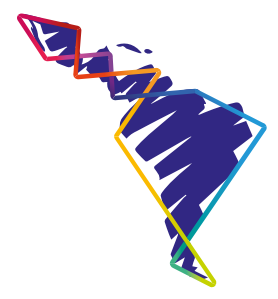

\title{
Los exilios y presencia en Costa Rica de nicaragüenses, durante las décadas de los 30 y 40 del siglo XX
}

\author{
The exiles and presence in Costa \\ Rica of Nicaraguans, during the \\ decades of the 30 s and 40 s of the \\ 20th century
}

\section{Exilados e presença na Costa Rica dos nicaraguenses, durante as décadas dos anos 30 e 40 do século XX}

\section{German Chacón Araya ${ }^{1}$}

"La memoria intenta preservar el pasado sólo para que le sea útil al presente y a los tiempos venideros. Procuremos que la memoria colectiva sirva para la liberación de los hombres y no para su sometimiento", Jacques Le Goff.

\section{Resumen}

Este artículo se enmarca dentro del proyecto de investigación "El Seminario Permanente "Exilio Iberoamericano”, y el Proyecto PAPIIT IA 600314 del CIALC, ambos de la UNAM (México). De este, la Universidad Nacional (Costa Rica) es contraparte a través del IDELA, como una ampliación del proyecto de investigación en el espacio investigativo que suponen las Jornadas del Exilio Iberoamericano. La investigación ha buscado incursionar en una temática poco estudiada, el largo exilio vivido en Costa Rica por nicaragüenses miembros del "Ejército de Liberación de Sandino y sus bases sociales”, posterior al asesinato de su máximo líder, en manos de los Somoza a principios de la década de los 30, quienes no renunciaron a derrotar la dictadura y participaron en golpes de mano a las fuerzas somocista, hasta el triunfo de la Revolución Sandinista, durante 49 años vivieron un exilio particular, incorporados en la defensa de las Garantías Sociales y el

1 German Chacón Araya. San José 1954, Sociólogo, investigador y académico, en la Universidad de Costa Rica (UCR), Universidad Estatal a Distancia (UNED) y Universidad Nacional (UNA), Costa Rica. Doctor en Estudios Latinoamericano, con énfasis en Pensamiento latinoamericano por la Universidad Nacional de Costa Rica. ORCID: https://orcid.org/0000-0003-4728-7873 
Código de Trabajo de Costa Rica, luchando como milicianos en la coyuntura que supuso la guerra civil de 1948, donde gran cantidad ofrendó su sangre, por la patria que les acogió.

\begin{abstract}
This article is part of the research project "El Seminario Permanente-Exilio Iberoamericano" (translated as "The Permanent Seminar-Ibero-American Exile"), and the PAPIIT Project IA 600314 of CIALC, both from UNAM (Mexico). The Universidad Nacional (Costa Rica) is counterpart of these projects through IDELA, by expanding the scope of investigation within the Jornadas del Exilio Iberoamericano (translated as Ibero-American Exile Journeys) research project. The present investigation has sought to venture into a sparsely studied subject: the long exile lived in Costa Rica by Nicaraguan members of the "Ejército de Liberación de Sandino y sus bases sociales" (translated as "Sandino Liberation Army and its social bases"), after the murder of its maximum leader, in the hands of the Somozas in early the 1930s. These individuals did not renounce defeating the dictatorship and participated in clobbering the Somocista forces, until the triumph of the Sandinista Revolution; for 49 years they lived a particular exile, incorporated in the defense of Costa Rica's Garantías Sociales (translated as Social Guarantees) and Código de Trabajo (translated as Labor Code), fighting as militiamen at the juncture that led to the civil war of 1948, where a large number offered their blood, for the homeland that welcomed them.
\end{abstract}

Keywords: Exile; Nicaraguans; Costa Rica; Presence.

\title{
Resumo
}

Este artigo é parte do projeto de pesquisa "El Seminario Permanente-Exilio Iberoamericano" (traduzido como "O Seminário Permanente-Exílio Ibero-Americano") e o Projeto PAPIIT IA 600314 da CIALC, ambos da UNAM (México). Desses projetos, a Universidade Nacional (Costa Rica) é uma contrapartida do IDELA, como uma extensão do projeto de pesquisa no espaço de pesquisa que envolve as Jornadas del Exilio Iberoamericano (traduzido como Dias Ibero-Americanos do Exílio). A investigação procurou se aventurar em um assunto pouco estudado: o longo exílio vivido na Costa Rica por membros nicaraguenses do "Ejército de Liberación de Sandino y sus bases sociales" (traduzido como "Exército de Libertação Sandino e suas bases sociais"), após o assassinato de seu líder máximo, nas mãos dos Somozas no início da década de 1930. Esses indivíduos não renunciaram à derrota da ditadura e participaram de golpes às forças Somocistas, até o triunfo da Revolução Sandinista; por 49 anos, viveram em exílio privado, incorporado na defesa das Garantias Sociais e do Código do Trabalho da Costa Rica, lutando como milicianos na conjuntura que levou à guerra civil de 1948, onde um grande número ofereceu seu sangue pela pátria que os acolheu.

Palavras-chave: Exílio; Nicaraguenses; Costa Rica; Presença.

\section{Resultados preliminares a octubre del 2019}

Este pequeño esfuerzo pretende apoyar los conocimientos que buscan, desde la teoría de los aprendizajes, desarrollar construcciones propias de la cultura latinoamericana, 
como un pensarse desde nuestras raíces, al efectuar una sistematización y lectura de los testimonios como una historia no escrita, con el fin de visualizar los exilios y presencias de nicaragüenses en Costa Rica, de forma tal que se puedan establecer las causas o motivaciones de esas diásporas, que en la mayoría de los casos se dieron de hecho, sin autorización consular o paso autorizado en puesto fronterizo, procesos migratorios que atienden parte de esa evocación de los exilios y presencias, como salidas forzosas.

Esta investigación permitió visibilizar cómo se dio la presencia nicaragüense en torno a las luchas sociales en las décadas de los 30 y 40 en Costa Rica, lo cual genera el espacio para concebir empeños investigativos, sobre este caso particular, como sujetos que requieren ser estudiados, como parte de una realidad latinoamericana. Más allá de una historia oficial surgida en la década de los 40, la cual fue escrita desde la perspectiva de los grupos vencedores, fundada por una intelectualidad socialdemócrata, que utilizó la institucionalidad para generar una verdad de los "triunfadores" durante la segunda mitad del siglo XX y parte de este. Al momento, apenas hemos venido haciendo esfuerzos por descodificar esos mensajes a partir de la recuperación de la memoria, como una labor importante e imprescindible, para visibilizar a esos actores invisibilizados a conveniencia de la historia oficial. Este rescate de la memoria histórica es una vía difícil, en donde va emergiendo, en las voces del colectivo, lo que no ha sido escrito, pero es parte de nuestra historia que ha sido contada innumerables veces para que no se olvide. Seguir este camino es ir al encuentro con la crítica de los otros sujetos, como un proceso dialéctico de encuentros y desencuentros, pero al fin un atrevimiento por ver y oír esas voces de los grupos vencidos como un derecho de escribir su historia en los libros de la patria.

Consideramos el exilio como una problemática propia o derivada del desarraigo forzado, en tanto una representación delimitada de emigración, es un fenómeno sociopolítico generalmente ligado a una lucha por el poder, en algunos casos propios de la lucha de clases, en donde un grupo se ve obligado a dejar su país, debido a situaciones de violencia política generalizada o conducentes al deterioro de las condiciones de un Estado particular. Desde la colonia, Costa Rica y Nicaragua han vivido en una constante relación, en algunos momentos tensas, pero sus pueblos han cruzado la línea fronteriza cuando así lo han requerido para subsanar sus necesidades o proteger su vida.

No se puede dejar de mencionar cómo actuaron los pueblos de Nicaragua y Costa Rica en la Guerra Centroamericana contra el "Destino Manifiesto y la Política Monroe”, como una política expansionista de corte imperialista, impulsada desde los Estados Unidos. Pese a las diferencias que existen en la lectura de estos 
acontecimientos, el pueblo "tico" y el "nica" pelearon y derrotaron a los mercenarios que pretendían esclavizarnos.

Con el fin de contextualizar el marco en que se produce el flujo migratorio objeto de este ensayo, debemos tener en cuenta que Nicaragua en el periodo de 1902 a 1933 va a sufrir tres intervenciones en manos de las fuerzas armadas de los Estados Unidos, las cuales se van a producir derivadas de la confrontación entre liberales y conservadores al interior del país. Estos grupos van a solicitar "ayuda" ( intervención norteamericana para resolver los asuntos domésticos), como se habría producido en el lejano 1856, cuando mediante el uso de fuerzas mercenarias, auspiciadas por el gobierno USA y con la premisa de la Doctrina Monroe, la cual podemos sintetizar en una frase muy usada por el colectivo gringo "América para los americanos", ellos habían intentado tomar Centroamérica, y fueron derrotados por los ejércitos centroamericanos.

Esas constantes luchas entre liberales y conservadores afectan los negocios norteamericanos en la región, dentro de los cuales uno de los más importantes es el tratado Bryan-Chamorro que consistía en la construcción de un futuro canal interoceánico a cambio de tres millones de dólares.

Los capitalistas gringos y sus lacayos entienden que aun cuando el canal de Panamá había entrado en funcionamiento para el año 1903, Nicaragua en la región continuaba siendo de interés estratégico, como lo sigue siendo en la actualidad.

Sin renunciar al tratado, los Estados Unidos procuran tener el derecho de establecer una base militar en el golfo de Fonseca, durante un período de 99 años, así mismo se le dan en arriendo las Islas del Maíz.

En mayo de 1926 se consintió la intervención militar norteamericana. Desembarcaron 3900 soldados, 865 marines y 215 oficiales, y anclaron 16 barcos de guerra, a solicitud del entonces presidente Adolfo Díaz Recinos².

¡Nicaragua, santa tierra de soldados y poetas! Si hoy es humillada y uncida al canibalismo del imperialismo yankee, muy pronto sonará la hora de tu gloria y redención. (La Prensa, 1926, p. 12)

Augusto Cesar Sandino (1895-1934) fue el fundador y estuvo al frente del Ejército Defensor de la Soberanía Nacional de Nicaragua, dio una lucha por la liberación

2 Adolfo Díaz Recinos nació en la provincia de Alajuela cantón de Esparza, Costa Rica, fue administrador de empresas y político nicaragüense, que ocupó la presidencia de Nicaragua en dos ocasiones, primero entre el 9 de mayo de 1911 y el 1 de enero de 1917 y luego desde el 14 de noviembre de 1926 hasta el 1 de enero de 1929

236 Revista Latinoamericana de Derechos Humanos 
de Nicaragua continuadamente durante seis años, de 1926 a 1932, periodo en el que se propuso derrotar al ejército de ocupación de los Estados Unidos, acantonado en Nicaragua. Según estimaciones de la prensa, en ese periodo murieron más de mil personas, consignados como bandoleros. Concibe Sandino que los soldados norteamericanos están en su país para proteger los intereses estratégicos de los Estados Unidos.

En 1928, El Diario de Costa Rica publica la siguiente información:

Anoche se efectuó en esta ciudad la reunión provocada por un grupo de personas para constituir un comité pro-Sandino (...) Concurrieron a él buen número de ciudadanos costarricenses y de otras nacionalidades, en el deseo de darle a ese movimiento un carácter americanista, dejando una clara evidencia de que los asuntos nicaragüense ligados a la lucha anti imperialista eran parte de la realidad costarricense. (Diario de Costa Rica, 1928, p. 5)

En el número 14 de Repertorio Americano de marzo de 1928, se publican varios artículos sobre la intervención norteamericana en Nicaragua. Sobresale la carta de Augusto César Sandino donde llama a conformar la Unión de Centroamérica, y cierra esta indicando que a esta fecha no ha recibido su ejército ninguna derrota.

También es necesario referirse al puñado de hombres costarricenses y nicaragüenses encabezados por el padre $\mathrm{Volio}^{3}$, quien a principios de la primera década del siglo XX, fusil en mano, se afilia a las tropas del General Sandino, combate en Chinandega y sale herido en el campo de batalla.

Volio es un personaje muy particular, recién llegado de Europa, pronunció un sermón en la parroquia de Heredia en homenaje a León Tolstoi. Meses después nació la leyenda: Volio se fue como sacerdote y regresó como el General. Este es el Volio antiimperialista, latinoamericanista y guerrillero.

Por su parte, en el marco que supuso la Sexta Conferencia Panamericana celebrada en la ciudad de la Habana en el año 1928:

... Augusto Cesar Sandino, el "General de hombres Libres", supo expresar su indignación respecto a la intervención norteamericana en los asuntos de una república

3 Jorge Volio Jiménez. Político, militar y sacerdote costarricense, combatió Nicaragua al ejército de los Estado Unidos la par del General Sandino. Fue el padre de la primera Ley de seguros de accidentes de trabajo. Dedicó parte de su vida a la enseñanza y a defender sus ideas con una gran fuerza y poder de convencimiento. Sus acciones y palabras dejaron una marca en la historia de Costa Rica durante el siglo XX. Declarado por la Asamblea LegislativaBenemérito de la Patriapor Acuerdo 2624 de 2 de marzo de 1989 y publicado en la Gaceta 76 de 20 de abril de 1989. 
latinoamericana, con el acantonamiento de un ejército extranjero en su territorio, plantea esto como una afrenta no solo para el país que busca liberar, sí no que además afecta la independencia panamericana, sus palabras tienen eco en los países ahí presentes y logra el apoyo de más de 145 representantes, lo que afecta la imagen de Washington, en el plano internacional y el tener que estar justificando las bajas impuestas por el "El Ejercito Defensor de la Soberanía Nacional de Nicaragua, obligan al presidente Herbert Hoover a poner fin a la ocupación, pese a los súplicas de su par nicaragüense de mantenerlas, retiró a las tropas el 2 de enero de 1933. (Selser, 1984, p. 126)

Con el fin de vertír luz sobre este personaje, es necesario tener en cuenta cuáles fueron sus motivaciones ideológicas. Sobre la influencia del marxismo en su organización se refería de la siguiente forma:

En distintas ocasiones se ha tratado de torcer este movimiento de defensa nacional, convirtiéndolo en una lucha de carácter más bien social. Yo me he opuesto con todas mis fuerzas. Este movimiento es nacional y antimperialista.

Mantenemos la bandera de libertad para Nicaragua y para toda Hispanoamérica. Por lo demás, en el terreno social, este movimiento es popular y preconizamos un sentido de avance en las aspiraciones sociales.(Sandino, p. 293.en Selser, 1984).

[En agosto de 1933] Sandino lanza la Suprema Proclama de la Unión Centroamericana la cual dedica a Morazán, como símbolo de unidad, exponiendo sus ideas políticas en una constitución, en ellas denuncia el servilismo de los gobiernos del istmo ante Estados Unidos y declara abolida la Doctrina Monroe. (Díaz, 2009, p. 140)

El año 1933 está marcado en la historia del continente; es electo Franklin D. Roosevelt como presidente de Estados Unidos; los delegados de la nueva administración conversan con Sandino, lo invitan a negociar con el gobierno nicaragüense, con fin de entregar las armas y propiciar el retorno a la vida civil, él "acepta”, no sin antes preparar, en algún lugar del norte de Nicaragua, una retaguardia armada, la que iba siendo rodeada por elementos de la Guardia Nacional, es de suponer delaciones internas o de los campesinos.

El 21 de febrero de 1934, teniendo en cuenta la situación y presiones, acepta una invitación para acudir al palacio presidencial, con fin de seguir buscando una mejor calidad de vida para el pueblo nicaragüense y consolidar la paz. Después de la cena, a unas cuantas cuadras de la casa presidencial, fue emboscado y asesinado por Anastasio Somoza, jefe de la Guardia Nacional y sobrino del expresidente José 
María Moncada. Es asesinado porque su prestigio dentro y fuera de Nicaragua era una amenaza para la burguesía regional y para los intereses de Washington.

$\mathrm{Al}$ instaurarse la dictadura Somocista en los años 30 del siglo pasado, miles de combatientes del Ejército de Defensa de la Soberanía Nacional y su base social cruzaron la frontera con Costa Rica y se integraron como fuerza de trabajo, principalmente en las bananeras. Ahí se ligaron a las luchas que había emprendido el Partido Comunista de Costa Rica, sobre todo en los sindicatos bananeros y participaron en la Gran Huelga Bananera en 1934, dirigida por Manuel Mora, Carlos Luis Fallas, Jaime Cerdas, entre otros.

El censo de población de Costa Rica de 1927 estimaba que en el país residían 10 642 nicaragüenses, para 1944, el número estimado de nicaragüenses en Costa Rica oscilaba entre 30000 y 50000 .

Estas personas exiliadas o migrantes lograron llegar por su cuenta, sin apoyo familiar o de organizaciones y se agruparon a partir de su identidad territorial, como una forma de legitimarse.

Es importante hacer notar que en el año 1942, afrodescendientes nicaragüenses "negros" habían sido incluidos dentro de la lista de "razas indeseables', junto con los chinos, árabes, turcos, sirios, gitanos y "coolies" no podían ingresar a Costa Rica. ${ }^{4}$

Para 1944, los nicaragüenses tenían creado un capítulo afiliado al PSN en San José, anunciándolo con la publicación del "Manifiesto para todos los Emigrantes Nicaragüenses en Costa Rica" en el periódico Trabajo, con lo que se demostraban los lazos entre trabajadores nicaragüenses y costarricenses y la izquierda. En la entrevista, Manuel Mora Salas 5 este plantea que "la formación ideológica de algunos cuadros se les dio en la escuela de formación del Partido Vanguardia Popular, inclusive indicó que entre otros habría estado Carlos Fonseca Amador”, en sus propias palabras: "esto debe verificarse".

Días antes de que se movilizara la columna liniera, se podía leer en la prensa costarricense descargos de nicaragüenses, que se veían afectados en sus planes de utilizar Costa Rica como retaguardia. En el Diario de Costa Rica, del 18 de febrero, 1947 aparece la siguiente publicación:

4 Costa Rica, Colección de leyes y decretos, Decreto no. 4 del 26 de abril de 1942. Esta ley se mantuvo en pie hasta 1960, cuando fueron removidos de la legislación costarricense todos los límites migratorios basados en La raza: Colección de Leyes y Decretos. Ley n² 2694 del 26 de noviembre de 1960.

5 Hijo del fundador del partido comunista de Costa Rica, "Comandante Ramiro" 
Exiliados nicaragüenses negaron su participación en cualquier complot costarricense y enfatizaron su intención de derrocar a Somoza. Rosendo Argüello Ramírez escribió una carta al Diario de Costa Rica negando vehementemente cualquier intento de interferir en la política costarricense y en complots en contra de Vanguardia Popular. Él declaró que solo los costarricenses tratan los problemas de Costa Rica, que la oposición nunca apoyaría la intervención nicaragüense, y que los nicaragüenses tenían suficiente con que preocuparse dentro de su propia nación. También explicó que las armas estaban previstas para usarse en Nicaragua como parte de un plan para derrocar a Somoza, y agregó que la elección de Leonardo Argüello había convencido a los revolucionarios de posponer sus planes.

La obra de Meléndez Ibarra, la "Columna Liniera" (Ediciones Revolución”, 7 de mayo de 1969), busca rescatar la "otra" historia, hace una defensa de los inmigrantes nicaragüenses, que puede ser entendida como una acción desesperada propia del desterrado:

Eran los días en que la reacción atacaba reciamente la Reforma Social y en las altas esferas se hablaba de derribar al Gobierno de don Teodoro Picado y sigue diciendo Meléndez "era un día del mes de septiembre del año 1947, empezando la noche, por el cuadrante de la finca "Guanacaste", circuló inesperadamente la noticia de que "Calufa" estaba alli. (Meléndez; 1969, p. 6) y continuaba diciendo....

En su tribuna improvisada nos habla Calufa:

...el Partido ha resuelto que una columna de obreros bananeros y de campesinos pobres, marche a pie desde el sur del país hasta la capital y asista a la celebración del 12 de octubre en San José, para manifestar así su apoyo al Presidente Picado y a las Garantías Sociales y al Código del Trabajo. (Meléndez, 1969, p. 20)

Meléndez Ibarra busca dar un lugar a las mujeres exiliadas y vanguardistas, para lo cual describe la salida de la columna a partir de la siguiente visión:

Las mujeres con rápidos movimientos a las 3 de la mañana, de un lado a otro en las cocinas chorreando el café, moviendo la "burra" en los peroles para que no se quemara, calentando el pan; otras hacían tortillas; algunas freían "rebanadas" de plátanos; los hombres también estaban activos: se bañaban, se rasuraban; otros ya estaban desayunándose con su buen plato de "burra" y café calientitos; en fin, los viajeros se preparaban para un viaje largo y duro. (Meléndez, 1969, p. 22)

6 Carlos Luis FallasSibaja, nació en Alajuela el 21 de enero de 1909. Entre susobrasliterarias están: Mamita Yunai escrita en 1940, miembro de la dirección del Partido Comunista, unos de los dirigentes más sobresaliente de la década de los 40 del siglo pasado. 
Calufa y Eduardo Mora ${ }^{7}$ fueron designados por el Comité Central de Vanguardia Popular para aglutinar a trabajadores bananeros de la zona sur (Palmar Norte, Palmar Sur y Quepos), con el fin de marchar en apoyo al Gobierno de Picado ${ }^{8}$. La columna liniera estaba compuesta por 1600 hombres y 4 mujeres, y una gran cantidad de los marchantes era de origen nicaragüense. El presidente Picado informa a la dirección del Partido Vanguardia Popular: primero, que las fuerzas de seguridad, las cuales debían garantizar la entrada de estos trabajadores por Cartago, habrían desertado y, segundo, que debían buscar caminos alternativos porque iban a ser ametrallados, en tanto como lo expone el militante de Vanguardia Popular, Meléndez Ibarra, en el libro de marras, la prensa decía:

... que la ciudad sería invadida por una turba de forajidos comunistas, violadores, ladrones y asesinos, quienes llegaban a capturar el Gobierno, que los hombres hablaban de esconder a sus hijas y de guardar todo lo que tuviera algún valor, para que no lo robaran los comunistas, jefeados por Carlos Luis Fallas y Eduardo Mora. (Meléndez, 1969, p. 64)

Como lo expone Alemán en su artículo "Nicas belicosos": "La prensa cuestionó la competencia de los trabajadores descamisados y descalzos para cuidar las calles de la capital como si fueran ciudadanos con algo que defender" (Diario de Costa Rica, 25 de julio, 1947).

Según lo expone Díaz Arias, en torno al conflicto de ética y dinámica social, "la huelga le permitió [a la oposición] etiquetar a los Calderocomunistas como 'negros,' 'trabajadores bananeros,' 'comunistas,' o sólo 'nicaragüenses somocistas' para mostrarlos como 'Otros' a la comunidad nacional” (Díaz, 2009, p. 236).

La columna Liniera ingresó a la ciudad capital en la mañana del 12 de octubre de 1947, fue recibida por el proletariado como héroes, los panaderos les bridaban pan a su paso, algunos les daban la mano, actos que habrían sido de todos los días, a lo largo de la larga marcha, ya en el Parque Central, en el corazón de la capital, hicieron un arco con sus resplandecientes machetes del número 28, e invitaron a Manuel Mora a pasar este camino entre vítores. ${ }^{9}$

7 Miembro de la dirección de PVP, y hermano de del fundador del PC.

8 Fue Secretario de Educación Pública, Secretario de Fomento, Diputado por San José, Presidente del Congreso Constitucional y Primer Designado a la Presidencia. Durante su desempeño en estos últimos cargos fue escogido como candidato presidencial para la selecciones de 1944 por el llamado Bloque de la Victoria, alianza formada por el Partido Vanguardia Popular (comunista) y el Partido Republicano Nacional encabezado por el Presidente Rafael Ángel Calderón Guardia. Los resultados de los comicios fueron muy polémicos, aunque las cifras oficiales lo favorecieron ampliamente y se le declaró elegido como Presidente para el período 1944-1948.

9 Para ampliar esta fase de la historia, se les invita a revisar el libro "Los Proscritos" de la Dra. Macarena Barahona 
Y con el pasar del tiempo en el contaste trajín de la lucha por sus derechos, se involucran en la Guerra Civil de 1948, estos trabajadores nicaragüenses combatieron como vanguardistas para proteger el Código de Trabajo y las Garantías Sociales. Así, estos grupos "exiliados" lucharon por lo que consideraban sus derechos. Es más, Vanguardia Popular ayudó a los nicaragüenses a establecer el Partido Socialista Nicaragüense (PSN) en Nicaragua.

Es evidente que después de la llegada de la columna Liniera a la capital y tras haber sorteado emboscadas en su avance, y ante la manifiesta incapacidad del gobierno de Picado de brindarles protección como había sido acordado, pues ya no tenía condiciones para permanecer en el poder. Pese a los puentes que habrían puesto importantes personalidades, José Figueres y sus hombres estaban listos con elecciones, o no, en hacerse con el poder.

En un intento por lograr posesionar ante los costarricenses, una versión diferente de los nicaragüenses, Meléndez Ibarra: "comienza declarando que maestros, poetas, periodistas, hombres de negocios, trabajadores y campesinos; todos han contribuido al proyecto de la gran civilización de Costa Rica en el siglo XX" (Melendez, 1969, p. 75).

Una prueba de lo que se vivía en esa Costa Rica, la encontramos en la novela de Quince Duncan, Final de calle, en la cual nos dicen, entre otros elementos importantes, que "...los nicas que andan con nosotros no son los de Somoza. Los que están con Fallas y los linieros son sandinistas. ... Además, esos nicas son de aquí ... han vivido aquí por mucho tiempo, trabajando en las bananeras. Son trabajadores como uno" (Ducan, 2000, p. 63).

Es importante ver que entre estos exiliados está el insurrecto nicaragüense, Alfredo Noguera Gómez, quien, desde Costa Rica, lanza una audaz acción armada en contra de Somoza, acción que condujo al presidente Picado a permitir que la Guardia Nacional nicaragüense traspasara la frontera de Costa Rica, por lo que se le tildó como un lacayo de Somoza.

Actos como estos nos llevan a poder examinar cómo se sucedieron los hechos que llevan a la invasión de tropas nicaragüenses en el año de 1955, evidencian una relación directa entre los expresidentes Calderón Guardia y Picado con el dictador Anastasio Somoza García. Como fruto de esa complicidad, Rafael Ángel Calderón Guardia habría organizado una fuerza militar para invadir Costa Rica, la invasión estaba dirigida por Teodoro Picado, hijo, y el hijo de Somoza. Se han podido localizar algunos de los actores en esta confrontación, lo que permitirá recuperar, desde la oralidad, una visión que para entender cómo se produjeron los hechos del 55, como parte de una realidad del exilio, en una segunda parte de este esfuerzo. 
En 1948 entre los nicaragüenses surgieron dudas, con respecto a quién debería seguir, si a los comunistas o la Legión Caribe, pues esta última prometía liberar a América Latina de dictaduras y, entre estas, de la de Somoza.

Contaban en el partido con los viejos militantes que Manuel Mora había reclutado al General Tijerino ${ }^{10}$ en los telares "Saprissa". En principio se negaban, hasta que Manuel les convence y les entrega un revolver en señal de trato. En el entendido de la justeza de la causa, se integran al Estado Mayor Vanguardista. Otros exiliados y combatientes nicaragüenses se incorporan a Legión del Caribe, dirigida por José Figueres Ferrer, en ellos priva la intención de ganar la lucha en Costa Rica y marchar con medios y hombres a derrocar a Somoza. Según lo anota el historiador Carlos Enrique Alemán:

Las características que determinaron las actividades y los objetivos de la oposición exiliada [nicaragüenses] fue, en el análisis final, el origen social de su liderazgo, que era poco diferente del PLN, PLI o hasta los Conservadores. (Knut, 1993, p. 229).

Se puede inferir que al interior de exilio nicaraguense en Costa Rica había una profunda división producto de la lucha de clases: los más, es decir, los trabajadores urbanos y rurales, esos que llaman los marxistas el proletariado se ligan a la lucha por sus derechos, desde las filas del Partido Comunista de Costa Rica o Vanguardia Popular; los otros, pequeños burgueses o burgueses se afilian a las tesis de la legión Caribe, porque representa, de mejor forma, sus aspiraciones. Es probable que, como representantes de clase, vieran, en esas reformas sociales que llamaban comunistas, un riesgo a sus intereses de propalarse estas en Nicaragua; los cierto es que en los campos de batalla se dio una lucha fratricida, en la que murieron por ambos lados exiliados de un país hermano.

Dentro de esos nicaragüenses, que combatieron en las milicias comunistas en 1948 y forman parte de ese gran exilio nicaraguense, esta Adolfo García Barberena, quien, por esos avatares del destino, vivió en el barrio en que crecí, fui compañero en el colegio de sus tres hijos, dos hombres y una mujer. Este hombre, de más de un metro ochenta, de oficio zapatero, era el "coco" con que las familias de ese barrio guadalupano asustaban a sus hijos, cuando el partido era ilegal, con la frase "si no se portan bien o se van a dormir el nica García se los lleva”. Era un hombre misterioso, siempre se desplazaba en la penumbra ya fuera en la mañana o la noche, y siempre con jacket de cuero negro.

10 General nicaragüense Enrique Somarriba Tijerino, uno de los escasos sobrevivientes de la plana mayor de Sandino en las Segovia. 
Teniendo en cuenta esas vivencias, me pareció oportuno, con el fin de lograr una visión más objetiva, que fuera Manuel Mora Salas, hijo del fundador del Partido Comunista y benemérito de la patria, quien nos presentara la vida de este exiliado ${ }^{11}$ :

Adolfo García Barberena vino a Costa Rica en los años 40 y participó en la guerra civil de 1948. Desde ese momento se ligó al Partido hasta su muerte. Siempre conservó su militancia en el Partido, además de militar en el FSLN. Lo conocí siendo yo un niño pequeño y al llegar a la adolescencia estreché además una relación de amistad personal. Después de los 6 años, mi padre compró una casa en Barrio Cristo Rey y Adolfo García, conocido como Garcillón, o Nica García trabajaba y vivía ahí. Nos hicimos muy amigos y ambos iniciamos el estudio de radio técnica por correspondencia. En el colegio yo era buen estudiante en física y matemáticas y él era un hombre con cultura autodidacta y adquirida en su militancia. Así las cosas yo le ayudaba en la materia de física y matemáticas, él me empezó a enseñar boxeo y algo de lucha libre. Puedo decir que Garcillón fue mi primer instructor en materias de seguridad.

No manejo detalles, pero sé que Garcillón y otros compañeros participaron en 1959 en un movimiento armado, guerrillero, donde murió un compañero nicaragüense militante del partido de apellido Morales, en esta columna también participó Miguel Sobrado, ese movimiento fue muy pasajero.

En la entrevista con Mora, él expone que en 1977 y 1978, Garcillón se ligó al FSLN, a la línea Tercerista y llegó a ser uno de los tres jefes de una unidad militar creada por esa tendencia.

El habló conmigo y solicitó que se les ayudara en el proceso de instrucción, se designó a Antonio Naranjo y Jerónimo Venegas quienes aplicaron todos los conocimientos de su preparación internacionalista,logrando estructurar y formar una unidad con un nivel más alto que el tradicional en esa época para las unidades irregulares. Esos combatientes conformarían parte de la "columna "Jacinto Hernández" integrada por 120 hombres y 3 mujeres, al mando de los comandantes "Domingo", Adolfo García Barberena; "Rosendo", Oscar Benavides, y "Ernesto", Iván Montenegro. Su misión, abrir un nuevo flanco de batalla en Zelaya Central y en su momento, recuerdo, se habló en la radiocomunicación de la necesidad de quitar presión en la posición que dominaba el "Danto", Germán Pomares, en la toma de las ciudades del norte, tal y como nos lo presenta Jossy Alemán, 10 de julio de 2019 en la página de Facebook de la Gente, y continuaba diciendo en este espacio de rescate de la memoria Sandinista, que la misión fracasa, al caer en varias emboscadas efectuadas por la Guardia Nacional, la complicidad de sectores campesinos a fines al régimen de los Somoza, fueron

11 Entrevista efectuada el 3 de abril de 2019. 
factores que impidieron avanzar en este proceso, tano es así que aquellos buscaron refugio en estas comarcas murieron envenenados con "camotillo", una raíz venenosa que se mezclaba con la comida.

En palabras de Manuel Mora Salas, la unidad Jacinto Hernández penetró en Nicaragua, pero debido a un radio faro instalado en las armas, que habían sido vendidas a esa unidad antes de entrar a la zona de combate, la Guardia Nacional de Somoza tuvo siempre la ubicación geográfica de la unidad. Así las cosas, el hostigamiento y el ataque son constantes a la unidad en su movimiento hacia el norte, lo que condujo a la aniquilación casi total de la unidad, salvándose unos pocos.

Dice Mora Salas que por el trabajo de investigación efectuado por Emmett Lang, quien quería y respetaba mucho al Comandante Garcillón; se pudo exhumar su cuerpo.El cual mostraba evidencia de haber sido torturado salvajemente, él fue enterrado atado con alambres de púas a otro combatiente. En Nicaragua se le hizo un entierro hermoso con participación de la brigada internacionalista "Mora Cañas"12 , quien le brindo honores militares.

Manuel en sus palabras dice: "Garcillón era un hombre de gran talento. Fue zapatero, radio técnico, pintor de cuadros hermosos en óleo y acrílico. Era buen boxeador y luchador. Participó en las unidades de autodefensa del partido, dejó tres hijos. Fue un comunista heroico y un militante de nuestro partido inolvidable. Su recuerdo debe ser rescatado y su biografía investigada. Su ejemplo maravilloso debe educar a las nuevas generaciones".

Dentro de los procesos de rescatar la memoria, pedí a Antonio Naranjo, nieto de uno de los fundadores del Partido Comunista, miembro de la Dirección de la Comisión de Seguridad del Partido y representante ante la Comisión Política del Partido Vanguardia Popular en los años 80 , una entrevista, pero debido a su trabajo esto no fue posible por lo que acordamos que escribiera su testimonio, el cual presentamos a continuación ${ }^{13}$ :

La Historia de la Lucha Social y Anti Imperialista en Costa Rica estaría incompleta si no se tomara en cuenta la participación de una enorme cantidad de mujeres y hombres provenientes de distintos países, que se incorporaron activamente como militantes y colaboradores de la Juventud y del Partido ${ }^{14}$, quienes participando en las tareas regulares y también en las tareas del trabajo clandestino vinculadas a la

12 Brigada integrada por costarricenses, dirigida por el comandante Ramiro, que combatió en la década de los 80 , en norte y sur de Nicaragua.

13 Documento remitido el 01 de marzo de 2019.

14 Se refiere al partido Vanguardia Popular de Costa Rica. 
Comisión de Seguridad del Partido, tanto en el trabajo a lo interno del país como en el trabajo internacionalista.

Recuerdo a camaradas de Guatemala, El Salvador, Honduras, Panamá, Cuba, México, Colombia, Chile, Uruguay, Argentina, España, Holanda, Estados Unidos entre otros y, por supuesto, una gran mayoría provenientes de Nicaragua, donde el trabajo partidario clandestino nos ocupó intensamente muchos años, tanto antes como después del triunfo del FSLN contra la dictadura de Somoza en Nicaragua.

(Entrevista a Manuel Mora Salas,20 de octubre, 2019)

Naranjo, nos vuelve a recordar a su camarada nicaragüense Adolfo García Barberena, de la siguiente forma:

Este fue conocido como comandante Domingo. Era un comunista, militante del Partido y uno de los tres jefes de la columna guerrillera Jacinto Hernández del frente Sur Ernesto Chato Medrano.

El hecho de que lo ponga de ejemplo es porque él simboliza a esos seres humanos que dieron su vida por un mundo mejor. Al camarada Domingo lo recuerdo con mucho aprecio y respeto porque a mí me tocó trabajar con él, cuando la Comisión de Seguridad del Partido nos asignó tareas de capacitación en un período relativamente corto pero de mucha intensidad para convertir una columna guerrillera en un destacamento guerrillero, elevando cualitativamente sus posibilidades como unidad militar.

Y agrega:

Otro ejemplo de lucha, valor y entrega es el de Luz Mejía Vallejos, conocida con el seudónimo de Clara, monja colombiana que se incorporó a la Brigada Calufa ${ }^{15}$, cambiando su hábito por el uniforme verde olivo y su rosario por un fusil. Toda una muestra de solidaridad bajo el principio del internacionalismo proletario.

Corresponderá a los historiadores y organismos encargados rescatar los testimonios y dar a conocer una historia no contada que es de extraordinaria importancia para las nuevas generaciones, sobre todo, tomando en cuenta el rumbo de deshumanización que prevalece hoy día y porque como dice aquella famosa frase: aquel que no conoce su historia está condenado a repetirla.( entrevista a Antonio Naranjo, agosto, 2019)

15 La Brigada Calufa, estuvo constituida por más 300 hombres y mujeres mayoritariamente provenientes de la filas del Partido Vanguardia Popular dirigida por el comandante Ramiro, que entro en zafarrancho de combate 1979 y permaneció en Nicaragua en trabajos de formación e inteligencia. 
Se entrevistó a Israel Guillén González, miembro de la Comisión de Educación y de la Comisión de Seguridad del Partido Vanguardia Popular antes de la división. El conversatorio con él inicia recordando su trabajo político y de seguridad en la zona sur a la par del cabo Marchena, Pingüino y muchos otros luchadores obreros. Nos contaba de lo difícil que era estar lejos de la casa, sobrevivir durmiendo en un local y comiendo en una fonda, de una nicaraguense de esas que siempre estuvieron a la par de las luchas emprendidas por el partido, donde fue al igual que una gran cantidad de mujeres, correo, enfermera, y compañera en los choques con la policía.

Israel nos brinda un testimonio muy particular, el iniciar hablando sobre los pagos del salario recibido como funcionario y dice que era muy poco y siempre llegaba meses después, él llegó a deberle a la fonda 6 meses, y ya no quería ir por vergüenza a coger sus alimentos en ese lugar y que la compañera nicaraguense exiliada le decía: "algún día mi partido, usted o el sindicato me pagarán", Esa era la actitud de esos nicaraguense integrados a la comunidad costarricense.

Y continuó diciendo; "la gran salvada fue cuando llegó el Papa Juan Pablo II a visitar Costa Rica y en la imprenta Elena ${ }^{16}$ se les ocurrió sacar un afiche del pontífice para recoger dinero, lo cual fue un éxito económico y pude pagar la fonda y otras cosas. Como funcionario comunista, tuve que desplazarme a zonas alejadas de Ciudad Neyli, donde no era conocido, para vender el afiche de su santidad".

Dice Israel que recuerda a: Santiago Martínez quien nació en San Jorge de Rivas un 14 de abril de 1922. Muy pequeño vino a CR con su mamá a "picar hule" en los 40. En Golfito conoce a Meléndez Ibarra e inicia una actividad de ayuda y solidaridad a su país contra la dictadura somocista. Empiezan a vincularse al sandinismo desde muy jóvenes con Carlos Fonseca Amador y a actuar contra la dictadura. Luego se vincula, ya después del 77, al partido Vanguardia Popular. Siempre apoyó a los militantes del PSN y a todos los exiliados. Su casa fue casa de seguridad y oasis de los perseguidos que llegaban a Costa Rica.En su casa fueron recibidos Carlos Fonseca, Humberto y Daniel Ortega, Germán Pomares, Edén Pastora y muchos otros.

Otros nicaragüenses que conoció fueron el sastre de apellido Sandino, que trabajaba en Plaza Víquez, militó en el partido con Joaquín Rodríguez, zapatero de Cristo Rey, con los zapateros Miguel Fonseca, Daniel Abea, Francisco García (Pachica). Con Efraín Jiménez (Payin) y el cabo Isaías Marchena colaboró en la organización del movimiento sindical. ${ }^{17}$

16 Imprenta del partido Vanguardia Popular ubicada en San José.

17 Entrevista realizada en enero de 2019. 
El conversatorio con "Mao"18 nos revela el proceso de transculturización que genera el exilio cuando es masivo, en donde los grupos humanos que se ven obligados por ley de la inercia a compartir un territorio finito, como un cantón, distrito o barrio, para nuestro caso los nicaraguense y los ticos. Dice "Mao" que en los 40 y 50 del siglo pasado, Quepos debería de tener una población donde el $50 \%$ eran nicaragüenses o descendientes directos de estos, y se daban situaciones tan particulares como las fiesta que patrocinaba una hábil comerciante nicaragüense, la "Chepapichona, fiestas cercanas a la celebración de la "Purísima Concepción de María"

En su recuerdo quedó grabada la magnificente "rueda capitana" ${ }^{20}$, las luminarias de pólvora, las bombas de doble trueno, la gigantona y otros payasos que alquilaba Chepa, los cuales, según su decir, venían de Nicaragua.

Estas fiestas convocadas en honor a la Virgen eran la remembranza de sus recuerdos del terruño, reproducían, así, en Costa Rica, sus festividades. Como encuentros del desterrado se ofrecía un duplicado de la patria, se le brindaba al participante una gran variedad de platos como chancho con yuca, carne al vaho, vigorón, caballo bayo, bebidas como atolillo, arroz con piña, pinol y muchos otros platos propios de la gastronomía nicaragüenses, no podían quedar por fuera las fanfarrias y los bailongos, donde no faltaba la ingesta del ron Flor de Caña ${ }^{21}$ en cantidades industriales. Estas festividades, con permiso del jefe político del cantón, duraban como una semana y la policía debía ser reforzada por la gran cantidad de pleitos y hasta macheteados todos los días.

La cercanía a su patria, con las posibilidades de moverse entre países limítrofes con una frontera muy porosa, les permitió estar en contacto con sus familiares. Cuando el gobierno de Costa Rica, con la participación de organizaciones internacionales abrió la oportunidad para favorecer el retorno, no fueron pocos los nicaragüenses que optaron por la repatriación voluntaria patrocinada por el ACNUR, sobre todo en la década de los 80 .

Pero esos hombres y mujeres de las décadas de los 30 y 40, cuando no participaban de los golpes de mano a la dictadura de los Somoza, decidieron integrarse a la sociedad costarricense, manteniendo en pocos casos la doble nacionalidad. Aquellos

18 Víctor Mora B., empresario costarricense, que vivió en Quepos en los 50. (febrero,2019).

19 La gritería es una festividad nicaragüense en honor ala Purísimae Inmaculada Concepción de María surgida a fines del siglo XVIII. Esta fiesta religiosa nacional se celebra en todos los pueblos y ciudades deNicaragua, y en aquellos países donde existe una importante cantidad de ciudadanos de esa nacionalidad.

20 Es un juego mecánico, hace movimientos oscilantes y el centro lo constituye una gran figura femenina gigante.

21 La primera destilería fue construida en el ingenio San Antonio, en Chichigalpa,Nicaragua, en elaño1890. Fundadapor Francisco Alfredo Pellas, la compañía es dirigida hoy en día por la quinta generación de la familia Pellas. 
que tenían impedimentos de ingreso, procuraron pasar como costarricenses y poco o nada de su experiencia o razones de la salida obligada de su patria transmitieron a su prole; es más, en las conversaciones con descendientes de aquellos exiliados, aunque fueran militantes del Partido Comunista o no, eran muy reservados con respecto a su pasado, no querían recordar, haciendo una negación propia del exiliado como colectivo.

Quienes, por su cuenta o haciendo uso de los canales para la repatriación voluntaria, volvieron a la patria, según su propio criterio, no hicieron la mejor elección, pues tuvieron que enfrentar una realidad diferente: muchos de sus familiares y amigos no estaban en los caseríos de donde salieron, algunos abrían emigrado o murieron en los largos años de resistencia a la dictadura. Resultaban extranjeros en su tierra y señalados con el dedo inquisidor como "traidores", según me relato la señora Yadira, de Nueva Guinea, Atlántico nicaragüense. Vistas así las cosas, meses después de la repatriación centenares volvieron, no pudieron readaptarse a una nueva realidad, y los más afectados fueron sus hijos, para quienes su patria y sus redes sociales estaban en Costa Rica, ellos no eran nicaragüenses, de manera que esto fue un exilio dentro del exilio.

Los exiliados nicaragüenses, que desde el principio optaron por rehacer su vida en la patria que les dio cobijo, se integraron a la sociedad receptora, sus hijos dejaron el beisbol por el balón pie, cantaron el himno de la patria que les vio nacer; sus padres, en un proceso de transición, no perdían sus esperanza de que se diera la derrota de los Somoza y mantenían su ligamen desde la clandestinidad, en sus comités de base del Partido Vanguardia Popular, en los sindicatos, en los talleres de zapatería, donde entre la tertulia recibían formación para actos de sabotaje a la dictadura, o como el caso de Santiago Martínez, quien nació en San Jorge de Rivas y era colaborador directo en la red de apoyo logístico del FSLN.

Lo cierto fue que los días se convirtieron en meses, los meses en años y estos en décadas, tiempo suficiente para que las familias crecieran y, con ayuda del internacionalismo proletario, sus hijos pudieran cursar estudios en las universidades estales o en los países del bloque socialista, donde se graduaron como literatos, ingenieros, economistas, médicos, arquitectos, etc.

Uno de esos casos es el de los López Avendaño, que se graduaron en las universidades costarricenses, para efectos de este documento referiremos el de Olimpia, la cual obtuvo el Doctorado en Educación de la Universidad Estatal a Distancia, una Maestría en Sociología de la UCR y una Licenciatura en Ciencias de la Educación con énfasis en Administración Educativa de esta misma casa de estudios superiores. 
La Dra. López trabajó en el Centro de Evaluación Académica, fue profesora en la Facultad de Educación y desempeñó diversos cargos docente-administrativos, entre los cuales destacan: subdirectora y directora de la Escuela de Administración Educativa, directora de la Maestría en Administración Educativa, coordinadora del programa de investigación Gestión y Liderazgo Universitario del Instituto de Investigación para el Mejoramiento de la Educación Costarricense (IIMEC), miembro del Consejo Universitario por el Área de Ciencias Sociales (2000-2004), candidata a rectora, entre otros.

Reiterando lo que decía Méndez Ibarra: “... que maestros, poetas, periodistas, hombres de negocios, trabajadores y campesinos; todos han contribuido al proyecto de la gran civilización de Costa Rica en el siglo XX (Meléndez, 1969, p. 75).

Importante fue la forma en que esta diáspora busca resolver el destierro propio de los exiliados, ellos, los proletarios del campo y la ciudad de origen nicaragüense, como hemos podido analizar, encuentran en el seno del Partido Comunista y de sus comités de solidaridad espacios de gestión, para sus luchas y estrategias de sobrevivencia, al ser coincidentes con sus aspiraciones de una patria más justa. Sus abuelos y padres abrían participado de la defensa de las garantías sociales, entregado su sangre y creando vínculos con sus pares, hasta la derrota de la dictadura Somocista.

Sin embargo, es notorio que para muchos, como el nica García y muchos otros, fue un largo camino, de más de 30 años, lo que posibilito establecer estrategias de mediano y largo plazo, encontró posibilidades para el desarrollo de su hijos en los países socialistas por intermediación del Partido Comunista, o en las universidades costarricenses, propias de un proceso de integración solidario, donde no se habla del otro, sino de nosotros. Esta vinculación del exiliado tiene múltiples matices con características muy particulares como fenómeno social.

No existe una única verdad, son aproximaciones, cada interlocutor expone su historia, desde sus vivencias, matizadas por posiciones ideológicas derivadas de la vinculación de sujeto, con un grupo particular, pero esto permite, desde la memoria colectiva, tener una idea de lo que sucedió, en las diferentes etapas de este largo y en algunos casos interminable exilio, hasta dejar de serlo, al haber optado por integrarse en principio a partir de una ideología compartida. Atrás quedaron los campos de batalla, la sangre derramada, la tortura, el dolor de los caídos, el destierro y sus formas de llevarlo. 


\section{A manera de conclusión}

Exiliados nicaragüenses que vinieron a Costa Rica después de la muerte de Sandino lograron integrarse a un proceso socio cultural nuevo, al vencer sus temores en el quehacer cotidiano de la lucha por superar sus dificultades de vida, e integrarse a la defensa de las Garantías Sociales y el Código de Trabajo, como parte de una acción surgida para buscar un estadio superior, como ser humano, como aspiración propia del proletariado, sin renunciar a la lucha por la liberación de su patria de la dictadura Somocista. Probablemente, esa particularidad del exilio les permitió construir, en sus imaginarios, una doble agenda de vida, la propia de su ubicación en otro país y la del desterrado, en tanto colaborador desde las organizaciones clasistas, como parte de una causa abrazada por un ideal, la libertad.

Su integración a la vida política, desde su espacio gremial o partidario y la defensa de sus derechos a la par de sus pares costarricenses, los llevó a generar condiciones identitarias propias de un nuevo contexto, lo que permitió reconstrucciones sicosociales como parte de una prolonga permanecía, donde privaron desconfianzas hacia los otros, tratados como liberales o conservadores, divisiones que persistieron inclusive en el Frente Sandinista, hasta entrada la década de los 70.

Costa Rica, como nación democrática, y en particular los costarricenses, siempre estuvieron anuentes a apoyar las justas demandas de los exiliados nicaragüenses y permitieron el funcionamiento de diversas organizaciones desde los años 30, las cuales favorecieron el actuar y el tránsito de estos al Caribe y a México. Si bien los presidentes tenían simpatía por esos luchadores antisomocistas, ejercieron, cuando las circunstancia los obligó por imperio de la ley sus facultades, y muchos exiliados terminaron en las cárceles; no obstante, siguieron teniendo movilidad en el territorio nacional, donde pudieron gozar de seguridad para planear y ejecutar sus acciones, desde la hospitalidad que ofrecieron los gobiernos de turno y que permitieron el funcionamiento de sus redes, con los exiliados y costarricense antisomocistas.

Una muestra de esos actos de apoyo está reflejada en las revistas y periódicos de las organizaciones de izquierda, de las universidades y de la misma presan nacional.

Como lo hemos podido ver, muchos exiliados se quedaron e hicieron sus vidas y vieron crecer a sus familias y tuvieron una participación importante en la vida política, cultural y religiosa de Costa Rica desde tiempos de la colonia. Formando parte de la realidad costarricense, veamos algunos ejemplos:

1) Rafael Francisco Osejo, educador y político (1790-1848)

2) Bárbara Enríquez Díaz Cabeza de Vaca y Palacios, primera dama (1791-1831) 
3) José Sacasa y Méndez, abogado y político (1796-1847)

4) Ascensión Esquivel Ibarra, abogado, catedrático y político (1844-1923)

5) Clodomiro Picado Twight, científico (1887-1944)

6) María Romero Meneses, religiosa y beata (1902-1977)

7) Hernán Bolaños, futbolista (1912-1992)

8) Olimpia López Avendaño, educadora, científica social.

9) JoséMeléndez Ibarra, dirigente campesino, escritor.

10) Chester Zelaya Goodman, historiador

11) José Simeón Guerrero de Arcos y Cervantes, abogado

12) Manuel Barberena, abogado

13) Miguel Ramírez Goyena, científico, botánico y educador.

14) Pablo Jirón, músico y maestro organista

15) Pedro César, abogado

16) Rafael Ángel Calderón Fournier, abogado, presidente de la República (1990-1994)

\section{Referencias}

Acuña, Miguel. (1990) El 48. Litografía e Imprenta Lil.

Aguilar, M. H. (1981) Carlos Luis Fallas y el Partido Comunista de Costa Rica [Tesis de grado]. Escuela de Historia y Geografía, Universidad de Costa Rica.

Aguilar, M. (1982) Carlos Luís Fallas; su época y sus luchas. Editorial Porvenir.

Alemán, E. (2013). Nicas belicosos: Nicaragüenses en la guerra civil de Costa Rica, 1948. Anuario de Estudios Centroamericanos. Universidad de Costa Rica, 39: 111-141.

Alemán, J. (10 de julio de 2019). Facebook de la Gente, Nicaragua.

Barahona, M. (2018) Nuevos documentos de 1948. "Los proscriptos". Editorial Costa Rica.

Bolzman, C. (1996). Sociología del exilio. Un enfoque dinámico. El ejemplo de los refugiados chilenos en Suiza. Seismo.

Bolzman, C. (2009). Chilenos en Suiza. De una comunidad política a una comunidad de residentes. En Escriva A., Bermúdez, A. y Morales, N. (eds.), Migración y participación política. CSIC.

Cerdas, R. (1998) La otra cara del 48 [1 $1^{\text {era }}$ ed.]. Editorial EUNED.

Chacón, G. (2019) En voces de la embajada de México, 1959-1961. UNAM. 
Díaz, D. (2009) Social Crises and Struggling Memories: Populism, Popular Mobilization, Violence, and Memories of Civil War in Costa Rica, 1940-1948 [Tesis doctoral]. Universidad de Indiana.

Duncan, Q. (2000) Final de calle. Editorial Universidad Estatal a Distancia.

Fallas, C. (1955) La gran huelga bananera del Atlántico de 1934. C.G.T.C.

Knut, W. (1993). El régimen de Anastasio Somoza, 1936-1956. University of North Carolina Press.

La Prensa. (Sábado 27 de noviembre de 1926). Crónicas de Santa Ana. La oración por Nicaragua. La Prensa.

López, J.(2000). Los cuarenta días de 1948: la Guerra Civil en Costa Rica. Editorial Costa Rica.

Meléndez, J. (1969) La columna liniera. Ediciones Revolución.

Mora, M. (1980). Discursos 1934-1979. Editorial Presbere.

Selser, G. (1984) Sandino, general de hombres libres. Editorial Abril S.A., Buenos Aires

Picado, J. (2014) Los amigos venían del Sur. EUNED.

Repertorio Americano. (1928). Número de 14 de marzo de 1928. 
